\title{
Hutan Kota Dalam Kajian Tingkat Kenyamanan Bagi Masyarakat (Studi Kasus Hutan Kota Blitar)
}

\author{
Risma Dwi Atmajayani \\ Program Studi Teknik Sipil Universitas Nahdlatul Ulama Blitar, Indonesia \\ Email: rismadwiatmaja@gmail.com
}

\begin{tabular}{l}
\hline Tersedia Online di \\
\hline http://www.jurnal.unublitar.ac.id/ \\
index.php/briliant \\
\hline \\
\hline Sejarah Artikel \\
\hline Diterima pada 7 Juli 2020 \\
Disetujui pada 29 Agustus 2020 \\
Dipublikasikan pada 31 Agustus \\
2020 Hal. 627-635
\end{tabular}

Kata Kunci:

$\overline{\text { Hutan Kota; Persepsi Masyarakat }}$

DOI:

http://dx.doi.org/10.28926/briliant .v3i4.503

\begin{abstract}
Abstrak: Tujuan dari penelitian ini adalah untuk mengetahui secara pasti seberapa besar tingkat kenyamanan yang dirasakan pengunjung terhadap hutan kota. Seberapa besar tingkat kenyamanan pengunjung menjadi salah satu kajian yang penting harapannya jika memang pengunjung sudah merasakan tingkat kenyamanan yang tinggi ketika berada di hutan kota maka pada akhirnya dapat dipromosikan sebagai salah satu asset wisata andalan Kota Blitar dan tentu saja ini pasti akan memberikan dampak yang baik seperti penambahan Pendapatan Asli Daerah (PAD). Penelitian ini bertujuan untuk mengetahui tingkat kenyamanan hutan kota Blitar yang didasari pada kondisi suhu, kelembaban udara, luas dan tutupan tajuk pohon penyusun serta persepsi pengunjung terhadap fasilitas penunjang kenyamanan di hutan kota Blitar. Penelitian mengenai persepsi menggunakan metode survey dengan menggunakan kuesioner sebagai instrumen penelitian ditambah dengan wawancara dengan beberapa nara sumber. Jenis data yang
\end{abstract} dibutuhkan dalam penelitian ini adalah data primer dan data sekunder. Data primer yang diperoleh dari penelitian ini adalah melalui pengukuran temperature, kelembaban udara, jenis pohon, jumlah pohon/kerapatan, dan luas tutupan tajuk. Persepsi pengunjung terhadap kenyamanan lingkungan di Hutan Kota Blitar dapat diketahui dari hasil kuesioner. Faktor yang mendukung tingkat kenyamanan hutan kota adalah aksesbilitas, kondisi pohon, kesejukan, kebersihan, keindahan visual, fasilitas bangku taman. Dengan adanya perbaikan yang terus berlanjut akan semakin menambah fungsi dan nilai tambah dari hutan kota.

\section{PENDAHULUAN}

Hutan Kota adalah hutan atau sekelompok pepohon yang tumbuh didalam area kota atau pinggiran kota. Dalam arti yang lebih luas bisa beragam jenis tanaman keras atau pepohon yang tumbuh di sekeliling pemukiman. Salah satu manfaat hutan kota adalah untuk mengurangi kerusakan lingkungan kota yang diakibatkan oleh dampak negatif pembangunan. Selain itu juga mempunyai fungsi untuk perbaikan lingkungan hidup dan fungsi estetika seperti yang dikemukakakan oleh Salim (1984), Wirakusumah (1987) dan Hough (1990). Pembangunan fisik di daerah perkotaan sebenarnya dipergunakan untuk memenuhi pemenuhan kebutuhan hidup manusia tetapi karena keterbatasan akhirnya banyak menyita ruang terbuka hijau perkotaan. Hal ini menyebabkan rusaknya fungsi resapan air, banjir, kekeringan dan polusi. Pada kondisi seperti ini hutan kota sangat diperlukan untuk memperbaiki kualitas lingkungan kota.

Hutan kota terletak di Jalan Diponegoro yang merupakan jalan arteri kota Blitar dimana banyak dijumpai kendaraan yang melewati ruas jalan ini. Lokasinya 
masuk dalam wilayah kota, sehingga sangat cocok sebagai paru-paru kota yang semakin hari semakin dirasakan menurun fungsinya karena banyak polusi dengan meningkatnya jumlah kendaraan bermotor. Tujuan pembangunan hutan kota ini selain sebagai ruang terbuka hijau juga sebagai tempat wisata alam, rekreasi, olah raga, pendidikan, meredam kebisingan, mengurangi kecepatan angin, menghisap bau, dan penurunan emisi gas rumah kaca.

Melihat begitu banyaknya potensi yang dimilki hutan kota peneliti ingin mengetahui secara pasti seberapa besar tingkat kenyamanan yang dirasakan pengunjung terhadap hutan kota Blitar, mengingat jika pada awal mulanya tujuan pemerintah daerah membangun suatu konsep hutan kota pasti mempunyai tujuan yang baik. Seberapa besar tingkat kenyamanan pengunjung menjadi salah satu kajian yang penting harapannya jika memang pengunjung sudah merasakan tingkat kenyamanan yang tinggi ketika berada di hutan kota maka pada akhirnya dapat dipromosikan sebagai salah satu asset wisata andalan Kota Blitar dan tentu saja ini pasti akan memberikan dampak yang baik seperti penambahan Pendapatan Asli Daerah (PAD). Rumusan masalah yang diangkat dalam penelitian adalah: (1) Bagaimana tingkat kenyamanan Hutan Kota Blitar, (2) Bagaimana persepsi pengunjung terhadap tingkat kenyamanan fasilitas Hutan Kota Blitar. Tujuan penelitian: (1) Mengetahui tingkat kenyamanan Hutan Kota Blitar, (2) Mengetahui persepsi pengunjung terhadap tingkat kenyamanan fasilitas Hutan Kota Blitar.

\section{Definisi dan Manfaat Hutan Kota}

Menurut beberapa ahli hutan kota sebagai sejumlah vegetasi berkayu dan asosiasinya yang berada di dalam dan sekitar pemukiman penduduk berkisar dari komunitas kecil perdesaan hingga metropolitan (Miller, 1996). Keragaman tanaman yang ada pada hutan kota merupakan salah satu nilai lebih untuk lingkungan sekitar, karena tiap tipe tanaman yang mempunyai karakteristik tertentu mempunyai fungsi sendiri seperti menyerap air dan menyerap polusi. Hutan kota mempunyai fungsi untuk menjaga keseimbangan ekosistem lingkungan dimana tanaman sebagai keragamaan hayati menjadi salah satu komponen yang dapat menjaga ketersediaan oksigen dan menyaring polusi udara sehingga manusia bisa menggunakan udara yang layak dan bersih.

\section{Jenis Potensial Untuk Pengembangan dan Pengelolaan Hutan Kota}

Salah satu persyaratan untuk wilayah perkotaan adalah tersediaanya ruang terbuka hijau dimana bisa dipergunakan untuk kebutuhan rekreasi dan refreshing bagi masyarakat. Pengelolaan hutan kota harus dilakukan dengan baik oleh semua pihak, mengingat hutan kota mempunyai fungsi yang sangat vital seperti yang tertuang dalam Peraturan Pemerintah No.63 Tahun 2002. Selain fungsinya untuk menjaga kualitas lingkungan, hutan kota mempunyai fungsi yang tidak kalah penting yaitu sebagai sarana rekreasi dan interaksi. Tidak jarang warga masyarakat menggunakan hutan kota sebagai tempat untuk melepaskan diri dari segala kepenatan aktivitas, sehingga ketika akhir pekan tak jarang hutan kota penuh dengan pengunjung yang ingin bersantai sejenak melepaskan beban rutinitas kerja. Dalam pengelolaan hutan kota tidak lepas dari campur tangan masyarakat dan instansi terkait karena dengan adanya penataan yang tepat akan menambah nilai lebih dan fungsi hutan kota. 


\section{Aspek Kenyamanan Hutan Kota Suhu Udara}

Suhu merupakan alat ukur yang sangat tepat dalam mengidentifikasi tingkat kenyamanan suatu wilayah, jika suhu relatif suatu wilayah relatif normal atau bahkan lebih rendah dari kondisi normal maka dapat dinyatakan area itu sejuk/nyaman dan sebaliknya jika suhu relatif disuatu wilayah lebih tinggi dari kondisi normal maka dapat dinyatakan area tersebut panas/tidak nyaman. Dari kajian dapat diketahui bahwa tingkat kenyamanan suatu wilayah akan lebih nyaman pada area tajuk rapat yang banyak pohon.

\section{Kelembapan Relatif Udara}

Kelembapan relatif udara sangat berhubungan erat dengan suhu, semakin rendah suhu suatu wilayah maka tingkat kelembapan tinggi dan sebaliknya. Keragaman tanaman dengan tipe perakaran dan tajuk tertentu akan sangat berpengaruh terhadap kondisi fisik suatu wilayah. Tipe tanaman dengan perakaran yang kuat dan tajuk yang rapat tentunya sangat efektif dalam mengurangi kadar pencemaran udara dan juga sangat efektif dalam menyerap air. Kuantitas tanaman dengan karakteristik diatas apabila tersedia dalam jumlah yang banyak tentunya akan berpengaruh terhadap suhu disekitar area tersebut. Setiap wilayah memiliki kelembapan relatif yang tentunya berbeda, tidak bisa disamakan antara satu tempat dengan tempat lain.

\section{METODE}

Dalam penelitian ini data yang diambil berdasarkan pengamatan langsung selama penelitian dan wawancara dengan responden. Alat-alat yang digunakan dalam penelitian ini adalah thermometer digital, hygrometer, pita diameter dan kuisioner. Bahan yang digunakan pada penelitian ini adalah tegakan hutan kota Blitar dan kuesioner serta alat tulis. Jenis data yang dibutuhkan dalam penelitian ini adalah data primer dan data sekunder. Data primer yang diperoleh dari penelitian ini adalah temperature, kelembaban udara, jenis pohon, jumlah pohon/kerapatan, dan luas tutupan tajuk serta persepsi pengunjung terhadap kenyamanan lingkungan di Hutan Kota Blitar.

Pengukuran temperature dan kelembaban dilakukan didalam hutan Kota Blitar. Pengukuran dilakukan di 3 titik sesuai dengan kelas tajuknya, tajuk rapat (tegakan mahoni, tajuk sedang (area bermain), tajuk jarang (lintasan sepatu roda). Temperatur diukur pada 3 waktu, pukul 06.00, pukul 12.00 dan pukul 17.00. Metode penelitian survey jenis eksplorasi ini digunakan untuk melihat persepsi pengunjung menggunakan sumber data dan informasi utama yang diperoleh dari responden sebagai sampel penelitian dengan menggunakan kuesioner atau angket sebagai instrumen pengumpulan data ditambah wawancara dengan beberapa nara sumber. Sebanyak 75 responden dipilih secara acak dengan kriteria inklusi berumur 12-60 tahun. Kriteria tersebut dipilih dengan pertimbangan bahwa responden memiliki kemampuan dalam memahami dan menjawab pertanyaan yang diajukan. Data hasil wawancara diolah dengan pengelompokan, pengelompokan terbagi atas 4 kategori yaitu sangat baik, baik, cukup, dan buruk. 
Hasil pengelompokan kemudian ditabulasikan, dipresentasekan dan dideskripsikan.

\section{HASIL}

Berdasarkan hasil penelitian pengukuran suhu relatif dapat diketahui pada pagi hari dengan tajuk rapat berada pada angka $26,61^{\circ} \mathrm{C}$ dan pada tajuk jarang berada pada angka $27,2^{\circ} \mathrm{C}$. Pada tajuk rapat memiliki naungan yang sudah baik namun suhu udara belum dapat dikurangi secara maksimal sedangkan pada tajuk jarang kurang ternaungi sehinggga sinar matahari dapat masuk secara langsung pada permukaan tanah.

Kelembapan relatif yang diukur pada area hutan kota dilakukan pada 3 periode yaitu pagi hari (07.00), siang hari (13.00) dan sore hari (17.00). Kelembapan relatif yang didapatkan pada rentangan suhu $26,61^{\circ} \mathrm{C}$ pada tajuk rapat dipagi hari berada pada kriteria sedang dengan nilai kelembapan relative $88,36 \%$. Kelembapan relative yang didapatkan pada rentangan suhu $27,2^{\circ} \mathrm{C}$ pada tajuk jarang dipagi hari berada pada kriteria tidak nyaman dengan nilai kelembapan 93,21\%. Kemampuan struktur hutan dalam kota seperti vegetasi penyusun dengan perakaran kuat akan memberikan pengaruh yang cukup besar dalam hal kemampuan mereduksi sinar matahari yang masuk ke area hutan kota. Jika dilihat dari waktu pengamatan suhu udara pada pagi hari suhu udara cenderung rendah dan nilai kelembapan tinggi sehinggga nilai temperature humidity index akan rendah.

Persepsi masyarakat terhadap tingkat kenyamanan hutan kota terwakili oleh kuesioner yang dibagikan pada responden dimana mereka menjawab item pertanyaan yang terkait dengan hutan kota. Dapat diketahui bahwa persentase terbanyak sebesar $97,3 \%$ responden menjawab fungsi hutan kota sebagai peneduh dengan keragaman vegetasi yang baik. Aksesbilitas menuju hutan kota dirasakan sudah cukup memadai sehingga masyarakat yang ingin menuju lokasi tidak merasakan susah untuk mendapatkan transportasi umum, besarnya nilai persentase sebanyak 96\%. Pada kisaran persentase lebih besar dari $80 \%$ menunjukkan kriteria sangat baik. Untuk fasilitas lampu taman pada hutan kota berada pada nilai 77,3\%, dikisaran angka ini tingkat kenyamanan hutan kota pada kriteria baik. Nilai persentase yang dirasakan kurang adalah fasilitas parkir, hal ini dikarenakan masih terbatasnya area parkir sehingga banyak pengunjung yang parkir dipinggir jalan utama. Kriteria tingkat kenyamanan yang ditunjukkan dengan nilai persentase tersebut berada pada kriteria buruk. Nilai yang sangat baik sampai buruk mencerminkan tingkat kenyamanan hutan kota berdasarkan persepsi masyarakat.

\section{PEMBAHASAN}

\section{Tingkat Kenyaman Hutan Kota Blitar}

Perkembangan wilayah perkotaan yang sangat cepat dapat menimbulkan permasalahan lingkungan seperti meningkatnya suhu udara dan penurunan kualitas lingkungan. Penurunan kualitas lingkungan dipengaruhi oleh banyak faktor seperti polusi udara dan pencemaran sampah. Keberadaan RTH (Ruang Terbuka Hijau) diperlukan untuk menangani permasalahan tersebut. Tujuan dari penelitian ini adalah untuk mengetahui tingkat kenyamanan masyarakat dengan 
adanya hutan kota Blitar. Temperatur Humidity Indeks (THI) digunakan untuk mengetahui tingkat kenyamanan hutan kota.

\section{Analisis Karakteristik Pengguna hutan Kota dan Taman Kota Zona I}

Berdasarkan hasil wawancara dengan beberapa responden menyatakan bahwa sebaiknya fungsi hutan kota terus ditingkatkan khususnya dalam hal sebagai peneduh dan paru-paru kota. Meskipun demikian masyarakat berdasarkan hasil kuesioner terdapat sekitar 62,67 \% atau sebanyak 47 responden memilih fungsi hutan kota sebagai pusat interaksi dan komunikasi masyarakat, 37,33\% menjawab fungsi lainnya (refreshing, main). Sebanyak $48 \%$ atau 36 responden menjawab mengutamakan fungsi hutan kota sebagai sarana dan prasarana pengembangan pendidikan, 52\% menjawab fungsi lainnya (refreshing, main).

\section{Zona 2}

Begitu pula dengan zona 2, masyarakat lebih memilih fungsi RTH (Ruang Terbuka Hijau) sebagai area hijau untuk lebih diutamakan. Hal ini dilatar belakangi karena Ruang Terbuka Hijau yang masih terbatas dan untuk wilayah kota sendiri dominan akan gedung dan bangunan seperti gedung pendidikan dan pemerintah serta dekat dengan jalan arteri yang dilalui banyak kendaraan bermotor, sehingga pada zona ini fungsi area hijau sangat dibutuhkan.

\section{Zona 3}

Sementara itu pada zona ke 3, pilihan terkait RTH (Ruang Terbuka Hijau) yang paling banyak dipilih masyarakat adalah sebagai sarana rekreasi. Selain itu terdapat 85,33\% atau 64 responden menyatakan memilih fungsi sebagai payung dan peneduh, sedangkan 14,67\% memilih fungsi keindahan. Sebanyak $92 \%$ atau 69 responden menyatakan lebih memilih hutan kota dan taman kota sebagai sarana rekreasi dan komunikasi, sedangkan $8 \%$ hutan kota sebagai sarana (refreshing, main). Meskipun begitu, masyarakat juga mengharapkan peningkatan kualitas keamanan pada hutan kota di lokasi yang cukup ramai pengunjung. Dibawah adalah gambar tampak depan hutan kota saat dihari aktif dan saat dipagi hari dimana tampak hilir mudik kendaraan bermotor dan para pesepeda beristirahat sejenak disekitar kawasan hutan kota.

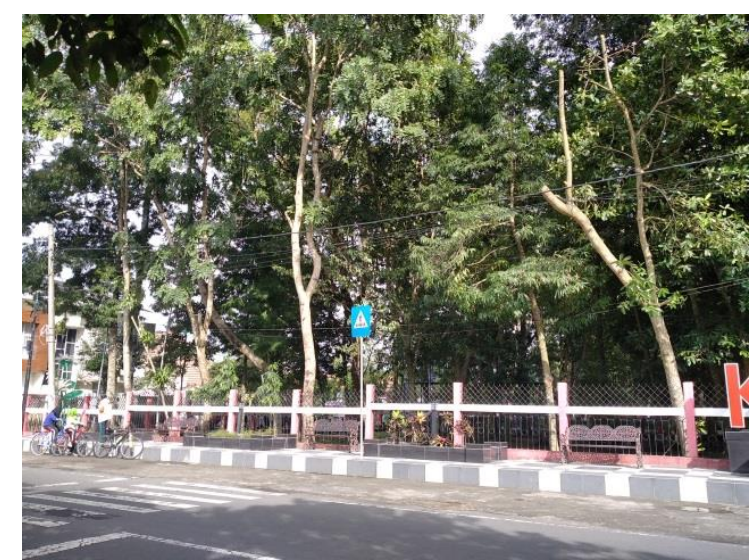

Gambar 1. Tampak depan hutan kota I 


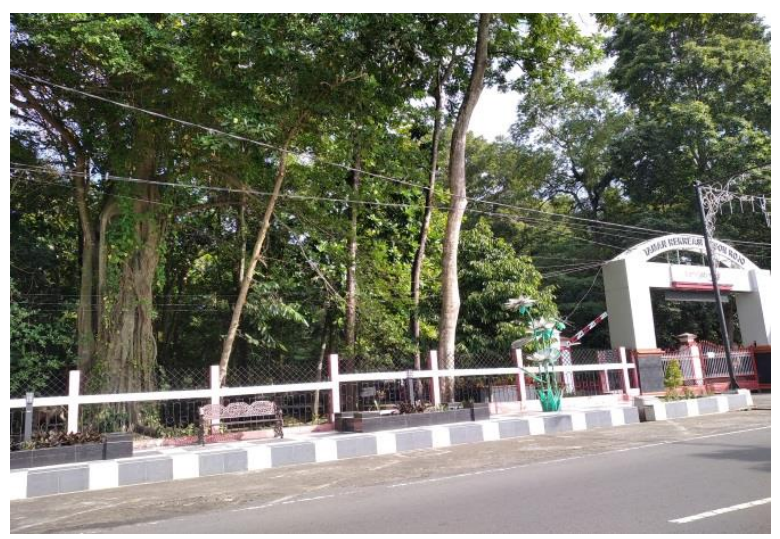

Gambar 2. Tampak depan hutan Kota II

Tingkat kenyamanan hutan Kota Blitar dipengaruhi oleh beberapa faktor:

a. Suhu Udara

Kondisi suhu udara disetiap wilayah tentunya akan berbeda, di kota Blitar relatif cukup banyak dijumpai adanya ruang terbuka hijau. Adanya pemukiman dan gedung pemerintahan juga memberikan andil yang cukup besar dalam menyumbangkan kenaikan suhu wilayah, sehingga dalam penataan wilayah perlu koordinasi dengan berbagai pihak terkait. Suhu di area hutan kota blitar merupakan salah satu komponen penentu iklim mikro yang mempengaruhi kenyamanan suatu wilayah dapat dijelaskan sebagai berikut :

Suhu udara pagi hari pada tajuk rapat $\left(26,61^{\circ} \mathrm{C}\right)$ dan pada tajuk jarang $\left(27,2^{\circ} \mathrm{C}\right)$. Dengan adanya hutan kota maka area di sekitarnya mendapatkan pengaruh yang cukup besar dimana ketika pagi hari suhunya relatif rendah dengan tempo waktu yang cukup lama sehingga senantiasa terasa tetap sejuk sampe siang hari.

b. Kelembapan Relatif

Adapun kelembapan relative udara (RH/Relative Humidity) hutan kota Blitar sebagai faktor kenyamanan sangat dipengaruhi oleh keragaman vegetasi dan suhu, pengukuran kelembapan relatif dilakukan dalam 3 periode yaitu periode pengukuran pagi hari (07.00 WIB), siang hari (13.00 WIB) dan sore hari (17.00 WIB) dapat dijelaskan sebagai berikut:

Area tajuk jarang mengelilingi area, tinggi rendahnya kelembapan udara disuatu tempat sangat tergantung dari faktor suhu dan faktor fisika yang lain. Dapat diketahui bahwa kelembapan relatif disekitar wilayah hutan kota cukup tinggi hal ini dikarenakan banyaknya tanaman dengan perakaran kuat dan tajuk pohon yang rapat sehingga menjaga suhu relatif disekitar area hutan kota tetap rendah dalam tempo yang cukup lama.

\section{Tingkat Kenyamanan Berdasarkan Persepsi Pengunjung Hutan Kota Blitar}

Berdasarkan hasil wawancara dan angket yang diberikan kepada pengunjung dapat diketahui bahwa pengunjung yang datang di hutan kota untuk keperluan rekreasi dan hiburan. Padatnya aktivitas sehari-hari mengakibatkan masyarakat membutuhkan ruang dan waktu untuk melepaskan kepenatan segala 
aktivitas yang dijalani, hutan kota merupakan salah satu alternative pilihan tempat yang bisa digunakan untuk keperluan tersebut.

Hal ini dikarenakan hutan kotamemiliki aneka vegetasi peneduh sehingga memberikan kesejukan bagi pengunjung dan aneka spot permainan yang bisa dipergunakan untuk bermain. Lokasi hutan kota yang berada dipusat wilayah Kota menyebabkan RTH ini mudah ditemukan dan merupakan salah satu tujuan masyarakat untuk refreshing dan rekreasi. Penataan tempat duduk, arena bermain, kandang hewan dan burung yang rapi dan bersih menyebabkan hutan kota terasa menarik untuk dilihat dan menyejukkan.

Tabel 1. Tingkat kenyamanan Hutan Kota Blitar berdasarkan persepsi masyarakat

\begin{tabular}{|l|l|l|l|l|l|l|}
\hline No & $\begin{array}{l}\text { Aspek } \\
\text { Kenyamanan }\end{array}$ & $\begin{array}{l}\text { Sangat baik } \\
(>80 \%)\end{array}$ & $\begin{array}{l}\text { Baik (70- } \\
80) \%\end{array}$ & $\begin{array}{l}\text { Cukup } \\
(60-69) \\
\%\end{array}$ & $\begin{array}{l}\text { Buruk } \\
(<60 \%)\end{array}$ & Lainnya \\
\hline 1. & Aksesbilitas & $96 \%$ & & & & $4 \%$ \\
\hline 2. & Kondisi Pohon & $97,3 \%$ & & & & $2,7 \%$ \\
\hline 3. & Keindahan visual & $93,3 \%$ & & & & $6,7 \%$ \\
\hline 4. & Keteduhan & $97,3 \%$ & & & & $2,7 \%$ \\
\hline 5. & Kesejukan & $94,7 \%$ & & & & $5,3 \%$ \\
\hline 6. & Kebersihan & $92 \%$ & & & & $8 \%$ \\
\hline 7. & $\begin{array}{l}\text { Fasilitas bangku } \\
\text { taman }\end{array}$ & $85,3 \%$ & & & $56 \%$ & $44 \%$ \\
\hline 8. & Fasilitas keamanan & & & & $54,6 \%$ & $45,4 \%$ \\
\hline 9. & $\begin{array}{l}\text { Fasilitas parking } \\
\text { area }\end{array}$ & & $77,3 \%$ & & & $22,7 \%$ \\
\hline 10. & $\begin{array}{l}\text { Fasilitas lampu } \\
\text { taman }\end{array}$ & & & & $57,3 \%$ & $42,7 \%$ \\
\hline 11. & Aroma & & & & \\
\hline
\end{tabular}

Berdasarkan tabel maka dapat dijelaskan bahwa terdapat beberapa faktor yang mempengaruhi kenyamanan pengunjung di RTH hutan kota Blitar antara lain, aksesbilitas, kondisi pohon, keindahan visual, keteduhan, kesejukan, kebersihan, fasilitas bangku taman, fasilitas keamanan, fasilitas parking area, fasilitas lampu taman, aroma. Aspek yang kurang menciptakan kenyamanan adalah fasilitas tempat parkir, fasilitas keamanan, dan aroma. Meskipun nilai THI (Temperature Humidity Index) hutan kota Blitar tergolong cukup, namun berdasarkan persepsi masyarakat masih tergolong nyaman pada aspek aksesbilitas, kondisi pohon, keindahan visual, keteduhan, kesejukan, kebersihan, fasilitas bangku taman dan penerangan yang berada pada rentangan baik.

Pada kuesioner yang dibagikan kepada para responden terdapat item pertanyaan yang dituliskan secara eksplisit tentang tingkat kenyamanan hutan kota, yaitu (1) Bagaimanakah tingkat kenyamanan hutan kota blitar : Nyaman / Tidak. Dari 75 responden yang diberikan kuisioner didapatkan hasil bahwa hutan kota Blitar berdasarkan persepsi masyarakat 66\% menyatakan nyaman atau sebanyak 49 responden menjawab nyaman, sedangkan 34\% menyatakan tidak nyaman atau 26 responden menjawab tidak nyaman. Dibawah tampak gambar 
area olah raga, bermain, play ground dan gazebo yang tersedia dihutan kota sebagai sarana yang mendukung kegiatan interaksi dan rekreasi masyarakat.

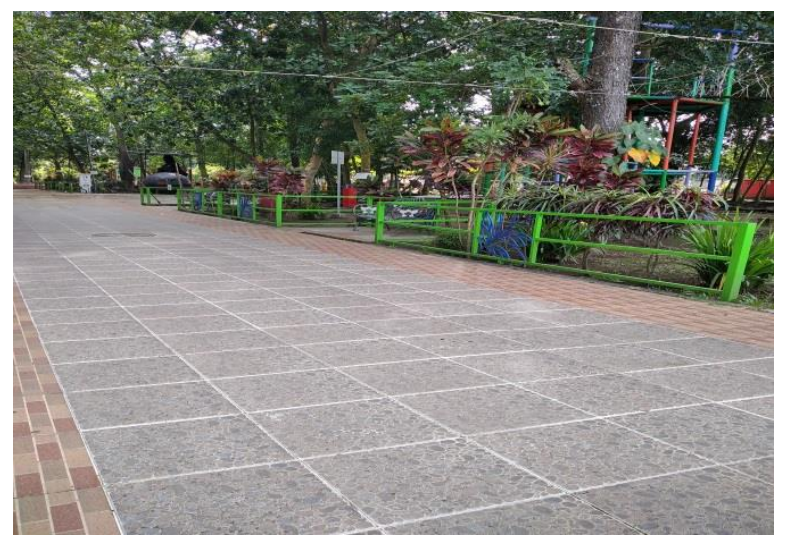

Gambar 3. Area olah raga dan bermain

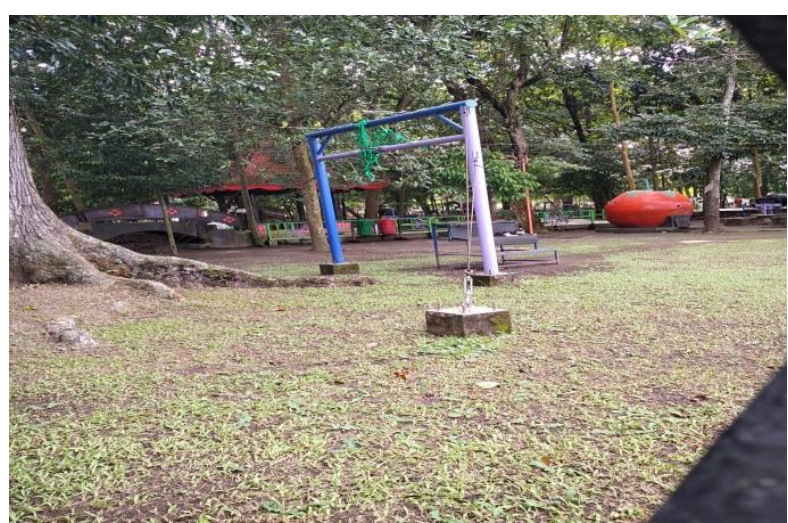

Gambar 4. Play ground dan gazebo

Berdasarkan persentase rata-rata aspek tingkat kenyamanan hutan kota maka didapatkan hasil persentase yang cukup akan tetapi untuk memaksimalkan fungsi dapat ditingkatkan oleh pengelola dengan perbaikan dan penambahan fasilitas seperti tempat parkir kendaraan, kotak sampah dan toilet.

\section{KESIMPULAN}

Tingkat kenyamanan hutan Kota Blitar dipengaruhi oleh beberapa faktor: a) Suhu Udara; Kondisi suhu udara dipengaruhi oleh keragaman vegetasi, di hutan kota Blitar terdapat banyak jenis vegetasi dengan karakteristik yang berbeda dan tidak dapat dipungkiri bahwa suhu berperan sebagai salah satu komponen penyusun iklim mikro yang mempengaruhi kenyamanan suatu wilayah. Adapun dari pengukuran suhu didapatkan hasil sebagai berikut: Suhu udara pagi hari pada tajuk rapat lebih rendah $\left(26,61^{\circ} \mathrm{C}\right)$ daripada tajuk jarang $\left(27,2^{\circ} \mathrm{C}\right)$. b) Kelembapan Relatif; Keragaman vegetasi yang tumbuh diarea hutan kota sangat berpengaruh terhadap tingkat kelembapan relatif. Nilai kelembapan relative udara (RH/Relative Humidity) hutan kota Blitar sebagai faktor kenyamanan diukur selama 3 periode dengan waktu pengukuran pagi hari (07.00 WIB), siang hari (13.00 WIB) dan sore hari (17.00 WIB) didapatkan data bahwa kelembapan relative udara (RH/Relative Humidity) pagi hari pada tajuk jarang lebih tinggi daripada tajuk rapat.

\footnotetext{
634 BRILIANT: Jurnal Riset dan Konseptual Volume 5 Nomor 3, Agustus 2020
} 
Tingkat kenyamanan berdasarkan persepsi pengunjung di hutan kota Blitar melalui kuesioner yang dibagikan kepada 75 responden didapatkan hasil bahwa $66 \%$ atau 49 responden menyatakan nyaman, sedangkan $34 \%$ atau 26 responden menyatakan tidak nyaman. Beberapa faktor yang mendukung kenyamanan adalah aksesbilitas, kondisi pohon, keindahan visual, keteduhan, kesejukan, kebersihan, fasilitas bangku taman dan penerangan yang berada pada rentangan baik.

\section{SARAN}

Pihak pengelola hutan kota dapat meningkatkan fungsinya dengan membangun dan memperbaiki beberapa sarana pendukung kegiatan seperti perbaikan tempat parkir, area bermain anak. Harapannya akan semakin banyak pengunjung yang antusias menggunakan area terbuka hijau dan menjadi salah satu alternatif rekreasi bagi masyarakat di wilayah kota.

\section{DAFTAR RUJUKAN}

Audy Evert, Slamet Budi Yuwono. 2017. The Comfort Level of Patriot Bina Bangsa Urban Forest In Bekasi City. Jurnal Sylva Lestari

Dahlan, A. 1992. Hutan Kota untuk Pengelolaan dan Peningkatan Kualitas Lingkungan Hidup. Jakarta. IPB-APHL

Fandeli, C. 2000. Pengelolaan Perhutanan Kota. Yogyakarta: Gadjah Mada Presss

Fandeli, C. Mukhlison, dan Kaharudin. 2004. Perhutanan Kota. Yogyakarta: Fakultas Kehutanan UGM

Peraturan Pemerintah Republik Indonesia. 2002. Nomor: 63, Tentang Hutan Kota. Jakarta. Sekretariat Negara Republik Indonesia

Rahardjo. 1983. Perkembangan Kota dan Permasalahannya. Jakarta: Bina Aksara

Rustam Hakim. 2004. Arsitektur Lansekap, Manusia, Alam dan Lingkungan. Jakarta: Penerbit Bina Aksara

Soemarwoto, Otto. 1983. Ekologi Lingkungan Hidup dan Pembangunan. Jakarta: Djambatan

Yuwana, T. 2010. Kajian Pengembangan Hutan Kota di Kota Tegal dengan Pendekatan Sistem Informasi Geografis. Skripsi. Yogyakarta: Fakultas Kehutanan UGM 